\title{
Adverse Event Following Immunization
}

National Cancer Institute

\section{Source}

National Cancer Institute. Adverse Event Following Immunization. NCI Thesaurus. Code C102470.

Any unfavorable or unintended symptom, sign, or disease including an abnormal laboratory finding) temporally associated with the previous administration of vaccine(s) that may or may not be considered related to the vaccine administration. Such events can be intervention related, dose related, route related, patient related, or caused by an interaction with other product(s) or procedure(s). 